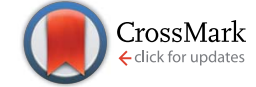

Cite this: RSC Adv., 2017, 7, 11701

Received 6th January 2017

Accepted 8th February 2017

DOI: $10.1039 / \mathrm{c} 7 \mathrm{ra00205j}$

rsc.li/rsc-advances

\section{Highly efficient electrochemical recognition and quantification of amine enantiomers based on a guest-free homochiral MOF $\dagger$}

\author{
Rui Kuang, Luyi Zheng, Yanhui Chi, Jingmin Shi, ${ }^{\star}$ Xuexue Chen \\ and Chengcheng Zhang
}

We facilely synthesized a novel guest-free homochiral metal-organic framework, $\left(\mathrm{Cu}_{4} \mathrm{~L}_{4}\right)_{n}\left[\mathrm{H}_{2} \mathrm{~L}=\mathrm{N}-(2-\right.$ hydroxybenzyl)-L-leucine] in space group $P 1$. The $\left(\mathrm{Cu}_{4} \mathrm{~L}_{4}\right)_{n}$ nanocrystals exhibit high electrochemical activity for rapidly discriminating chiral $\alpha$-methylbenzylamine enantiomers and quantitatively determining the enantiomeric excess in the chiral amine mixture.
Many important molecules in the modern pharmaceutical and agrochemical industries, are chiral-that is, they are not superimposable on their mirror image, the pair of asymmetric molecules are known as enantiomers. The recognition and quantification of enantiomers is a major challenge particularly owing to their identical physical and chemical properties in an achiral environment. ${ }^{1}$ In many cases, one of the enantiomers exhibits the desired responses while the other is inactive or even toxic. ${ }^{2-4}$ The present technology depends largely upon nuclear magnetic resonance (NMR), gas chromatography (GC) and high performance liquid chromatography (HPLC) based on homochiral stationary phases (CSPs), which is of particular importance for laboratories and industries in the discovery and development of enantiomeric substances and quality control of corresponding products. ${ }^{5-7}$ However, these methods require high concentrations of analytes, sophisticated operation, relatively expensive instrumentation, and GC and HPLC are also typically time-consuming. ${ }^{8,9}$ Molecularly imprinted polymers (MIPs) have more than 80 years of history, ${ }^{10,11}$ considerable advances have been made on the fundamental study. ${ }^{12,13}$ Although the approach behaves special desired selectivity because the MIPs create three-dimensional cross-linked polymers with tailor-made memory of the shape, size and functional groups for a template or target molecule, ${ }^{14,15}$ this sometimes also suffers from some problems, such as incomplete template removal, poor mass transfer, low binding capacity and slow binding kinetics, which restricts its applications in various aspects. ${ }^{16}$ In contrast, the electrochemical sensors can provide highly selective, low cost, fast speed, real time and on-line

College of Chemistry, Chemical Engineering and Materials Science, Collaborative Innovation Center of Functionalized Probes for Chemical Imaging in Universities of Shandong, Shandong Normal University, Jinan 250014, P. R. China. E-mail: shijingmin1955@gmail.com

$\dagger$ Electronic supplementary information (ESI) available: Full synthetic and experimental details. See DOI: $10.1039 / \mathrm{c} 7 \mathrm{ra00205j}$ operation. Unlike chromatographic instruments, the technology can be easily adapted for detecting a wide range and low concentrations of analytes, while remaining inexpensive. ${ }^{17}$ However, there are only a handful of progress at the present chiral sensing using this approach.

The key of the electrochemical chiral sensing is the material used to prepare the sensor's electroactive surface. The emerging chiral metal-organic framework (CMOFs) are the intriguing class of crystalline materials formed usually by the selfassembly of metal ions and chiral polydentate ligands. These materials are highly promising for electrochemical chiral sensors owing to ultrahigh surface area, precise network structures, fine-tuned chiral channels and pores, regularly ordered functionalities and host-guest interactions involved. ${ }^{18,19}$ At present, however, only a few achiral MOFs have been attempted as electrochemical sensors for detecting a few achiral analytes. ${ }^{20-22}$ Such as, Gassensmith et al. demonstrated that $\gamma$-cyclodextrin-derived CDMOF-2 is capable of measuring $\mathrm{CO}_{2}$ concentrations quantitatively in the presence of ambient oxygen. ${ }^{23} \mathrm{Wu}$ et al. developed a water-stable $\mathrm{Cu}-\mathrm{MOF}$, $\left\{\left[\mathrm{Cu}_{2}(\mathrm{HL})_{2}\left(\mu_{2}-\mathrm{OH}\right)_{2}\left(\mathrm{H}_{2} \mathrm{O}\right)_{5}\right] \cdot \mathrm{H}_{2} \mathrm{O}\right\}_{n}\left(\mathrm{H}_{2} \mathrm{~L}=2,5\right.$-dicarboxylic acid3,4-ethylene dioxythiophene) used for the simultaneous detection of ascorbic acid and L-tryptophan. ${ }^{20}$ In addition, there are few studies to incorporate the functionality of achiral MOFs and its derivatives into enzyme biosensor applications. ${ }^{24-26}$ To the best of our knowledge, until now no reports have been found regarding CMOFs for selective chiral detection. On the other hand, aiming at practical applications, the CMOFs must retain their structural integrity in both cases, the aqueous environment and the removal of the guest molecules trapped in the channels for creating empty pores and accessible metal sites. ${ }^{27}$ However, most CMOFs of current reports are susceptible to deterioration when exposed to water or even humid air, and during the conventional guest removal procedure of heating in vacuum. ${ }^{28}$ It is particularly challenging to render networks with 
chiral topologies robust to guest loss. ${ }^{29}$ The synthesis of guestfree CMOFs with highly water and air stability is also an extremely good choice.

Herein, we present the synthesis, structure of a novel guestfree CMOFs, that is, $\left(\mathrm{Cu}_{4} \mathrm{~L}_{4}\right)_{n}$, constructed from $\left(\mathrm{Cu}_{4} \mathrm{~L}_{4}\right)$ clusters using a enantiopure reduced Schiff base, $\mathrm{N}$-(2-hydroxybenzyl)L-leucine] $\left(\mathrm{l}-\mathrm{H}_{2} \mathrm{~L}\right)$ as a starting material. The CMOF exhibits high stability towards air and water. Remarkably, an electrochemical chiral sensor was easily obtained by a glass carbon electrode directly covered with $\left(\mathrm{Cu}_{4} \mathrm{~L}_{4}\right)_{n}$ nanocrystals without desolvation and further post-modification. The sensor behaved high electroconducting and distinctive oxidation signals for each enantiomer of $R(+)$ - and $S(-)$ - $\alpha$-methylbenzylamine (MBA). Not only is the sensor able to discriminate enantioselectively, but it also allows for the rapid quantitative determination of enantiomeric excess in the chiral amine mixture.

Single crystals of $\left(\mathrm{Cu}_{4} \mathrm{~L}_{4}\right)_{n}$ were readily obtained by mixing $\mathrm{CuCl}_{2} \cdot 2 \mathrm{H}_{2} \mathrm{O}$ and the ligand $1-\mathrm{H}_{2} \mathrm{~L}$ ( $N$-(2-hydroxybenzyl)-Lleucine), lithium hydroxide aqueous solution, acetonitrile and ethanol for 2 days at room temperature. To rapidly synthesize $\left(\mathrm{Cu}_{4} \mathrm{~L}_{4}\right)_{n}$ nanocrystals, we also developed a $2 \mathrm{~min}$, roomtemperature method, which was achieved by adding $\mathrm{Cu}(\mathrm{OAc})_{2}$ aqueous solution into the mixture of ligand $1-\mathrm{H}_{2} \mathrm{~L}$, lithium hydroxide aqueous solution, DMF and DMSO. The flaky nanocrystals were obtain in a high yield (73\%) without the need for any activation procedures. SEM images in Fig. 1a showed their micro-morphologies with a size of $\sim 500 \times 100 \times 90 \mathrm{~nm}$.

Single-crystal X-ray structural analysis revealed that $\left(\mathrm{Cu}_{4} \mathrm{~L}_{4}\right)_{n}$ crystallizes in the chiral space group $P 1$ and has guest-free chiral open channels (Fig. 1b). The asymmetric cluster of the framework consists of four penta-coordinated $\mathrm{Cu}$ (II) centers and four chiral L(II) ligands. Each $\mathrm{Cu(II)}$ center exhibits a squarepyramidal coordination geometry bridged by two phenolate $\mathrm{O}$ atoms (O1 and O4), two carboxylato $\mathrm{O}$ atoms (O3 and O8) and one secondary amine $\mathrm{N}$ atom (N1). Each L(II) ligand maintains a quatridentate bridging coordination mode. Each carboxylate group in L(II) ligands serves as a syn-anti bridge between $\mathrm{Cu}$ (II) ions to afford a $1 \mathrm{D}$ chain. Then the $\mathrm{Cu}(\mathrm{II})$ ions are further connected by the corresponding two L ligands through the phenolate $\mathrm{O}$ to generate a $2 \mathrm{D}$ sheet structure. The guest-free chiral channels are square-shaped, and phenyls on channels walls are perpendicularly with the coordination layers (Fig. 1c and $\mathrm{d}$ ).

The ideal materials as the electrochemical chiral sensing should possess not only precise framework structures, but also homochirality, specific porous properties and high stability in heat, air and water. The solid-state circular dichroism (CD) spectra of $\left(\mathrm{Cu}_{4} \mathrm{~L}_{4}\right)_{n}$ crystals and its enantiomer, $\left(\mathrm{Cu}_{4} \mathrm{~L}_{4}\right)_{n}{ }^{\prime}$ exhibit strong opposite Cotton effect around 234, 292 and $387 \mathrm{~nm}$, which confirmed the homochirality of $\left(\mathrm{Cu}_{4} \mathrm{~L}_{4}\right)_{n}$ (Fig. 2a). The
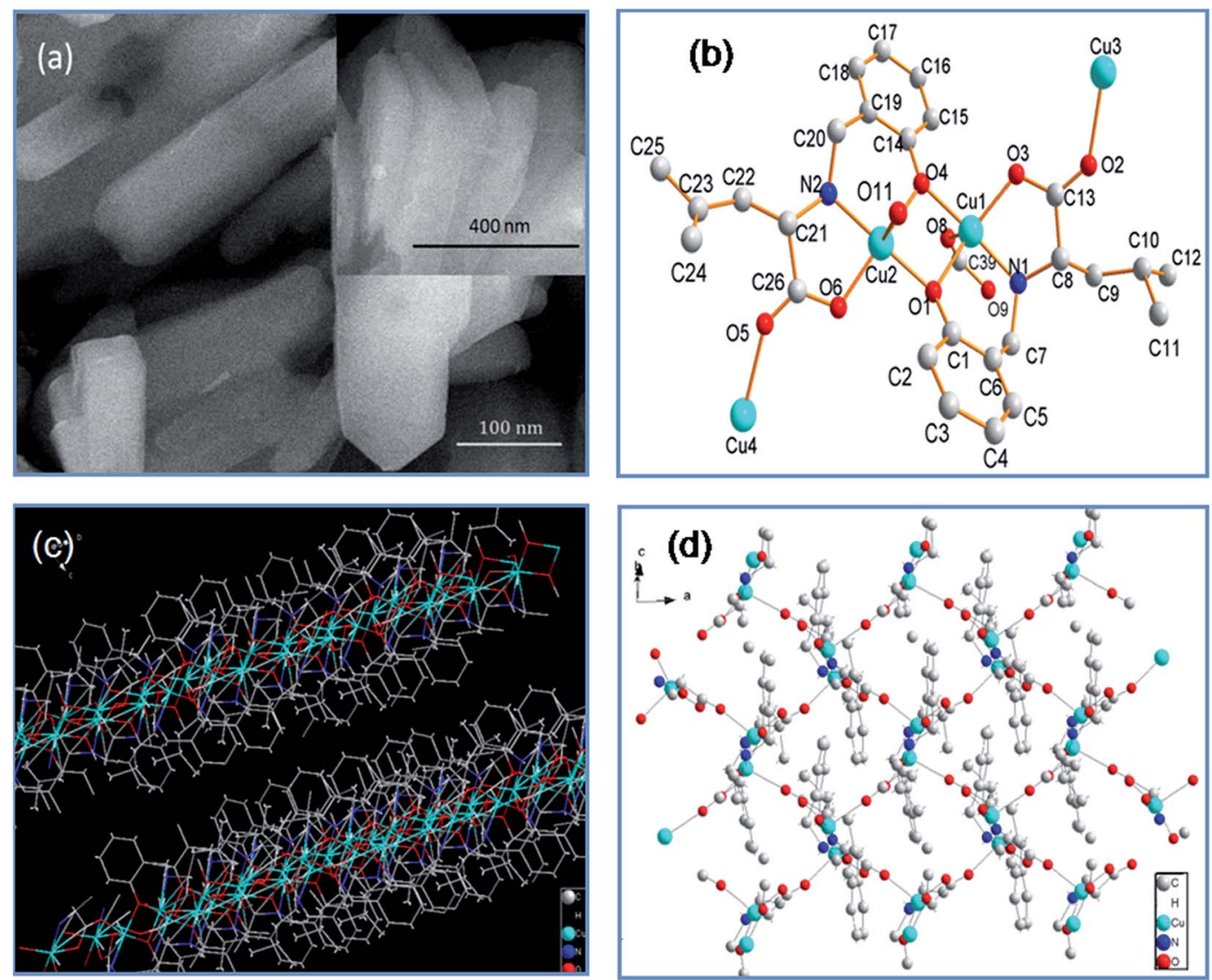

Fig. 1 SEM images of $\left(\mathrm{Cu}_{4} \mathrm{~L}_{4}\right)_{n}$ crystals with different magnifications (a). Local coordination environments of the $\mathrm{Cu}($ (I) center and the chiral ligands in $\left(\mathrm{Cu}_{4} \mathrm{~L}_{4}\right)_{n}$, hydrogen atoms are omitted for clarity (b). Side view of $2 \mathrm{D}$ sheet structure $(\mathrm{c})$. Framework structure of $\left(\mathrm{Cu}_{4} \mathrm{~L}_{4}\right)_{n}$ integrated, showing the microporous channels and the hydrophobic surface. Color codes: Cu red, N blue, C grey, $\mathrm{H}$ white (d). 

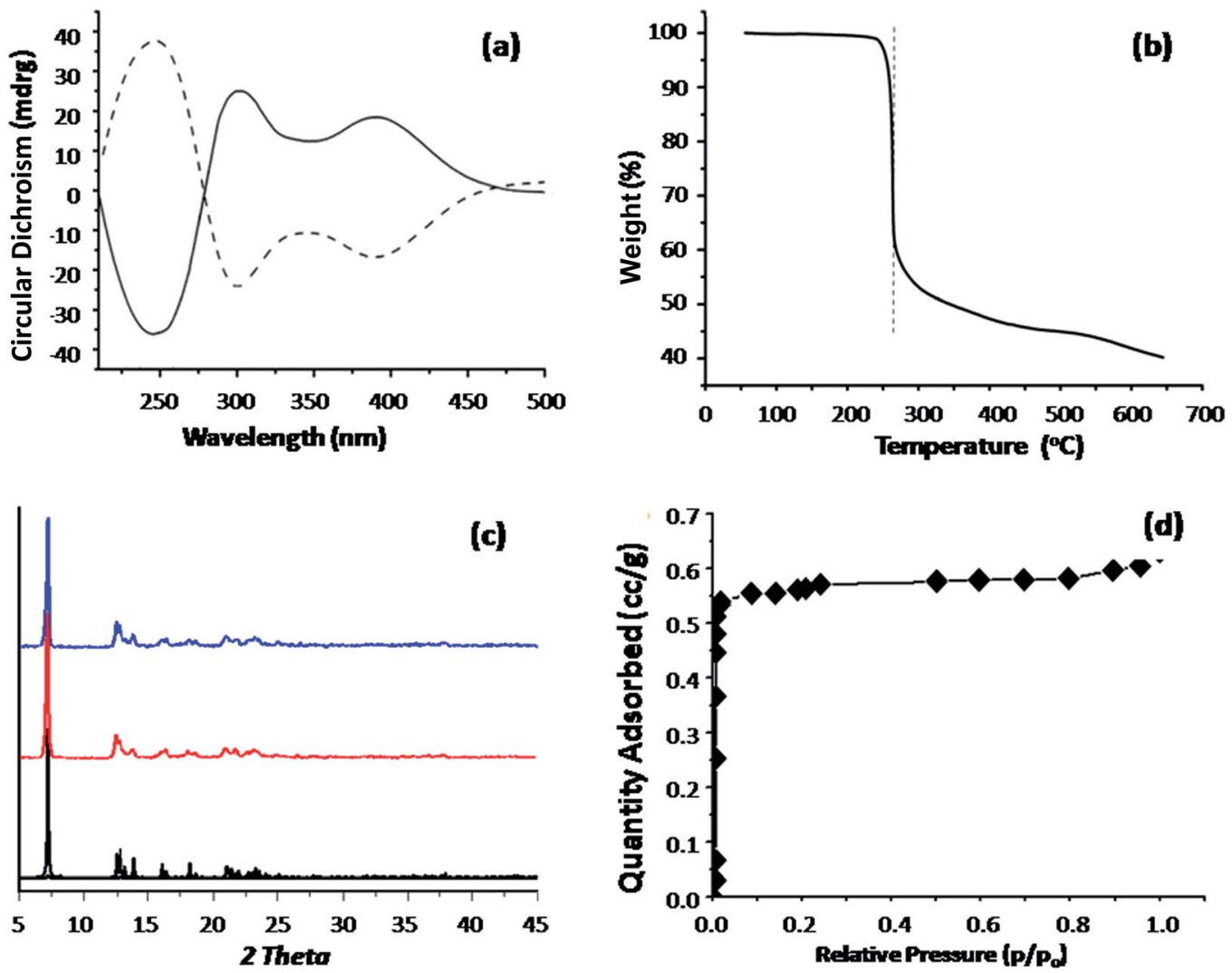

Fig. $2\left(\mathrm{Cu}_{4} \mathrm{~L}_{4}\right)_{n}$ properties: (a) CD spectra of $\left(\mathrm{Cu}_{4} \mathrm{~L}_{4}\right)_{n}$ (solid) in comparison with that of its enantiomer $\left(\mathrm{Cu}_{4} \mathrm{~L}_{4}\right)_{n}^{\prime}$ (dash); (b) TGA analysis; (c) PXRD patterns of simulated $\left(\mathrm{Cu}_{4} \mathrm{~L}_{4}\right)_{n}$ from the single crystal data (black), as-synthesized product for $110^{\circ} \mathrm{C}$ for $24 \mathrm{~h}$ (red) and after immersing into water for 2 weeks (blue); (d) nitrogen gas sorption isotherm at $77 \mathrm{~K}$.

polymeric lattice of $\left(\mathrm{Cu}_{4} \mathrm{~L}_{4}\right)_{n}$ is free-guest and can be retained upon heating at $280{ }^{\circ} \mathrm{C}$, which is supported by the thermogravimetric (TGA) analysis (Fig. 2b). After being suspended in water for a week and exposed in air for one month, the PXRD patterns of these crystals were still in conformity with the simulated one from the single-crystal data (Fig. 2c), indicating an excellent water and air stability of this CMOF. The porosity of $\left(\mathrm{Cu}_{4} \mathrm{~L}_{4}\right)_{n}$ was further probed by $\mathrm{N}_{2}$ sorption, follow a typical type I isotherm corresponding to micropores, and its BET surface area is $56 \mathrm{~m}^{2} \mathrm{~g}^{-1}$ (Fig. 2d).

Pure $\alpha$-MBA enantiomers are key building blocks and intermediates in a number of pharmaceutical and agromedical compounds that possess a wide range of biological activities. ${ }^{30}$ However, there is no report found concerning electrochemical detection $R(+)$ - and $S(-)-\alpha-$ MBA enantiomers, which may be due to its poor electroactivity. To evaluate the ability of our CMOF discriminating $\alpha$-MBA enantiomers, the electrochemical chiral sensor was assembled by coating $\left(\mathrm{Cu}_{4} \mathrm{~L}_{4}\right)_{n}$ on the surfaces of GCE. In particular, present $\left(\mathrm{Cu}_{4} \mathrm{~L}_{4}\right)_{n}$ is used without desolvation. In many instances, guest molecules filling in the pore of MOFs and solvent molecules coordinated at open-metal sites (OMS) of MOFs should be evacuated and decoordinated by an activation process prior to every use. ${ }^{31}$

The properties of the CMOF-functionalized electrodes were firstly tested by cyclic voltammetry (CV) in $\mathrm{K}_{2} \mathrm{HPO}_{4}-\mathrm{KH}_{2} \mathrm{PO}_{4}$ buffer solution ( $0.1 \mathrm{~mol} \mathrm{~L}^{-1} \mathrm{PBS}, \mathrm{pH}$ ). As shown in Fig. 3, the bare GCE behaves low and overlapped currents for $R(+)-\alpha$-MBA and $S(-)-\alpha-M B A$. In contrast, the modified electrode, $\left(\mathrm{Cu}_{4} \mathrm{~L}_{4}\right)_{n} /$ GCE causes a significantly increased oxidation current, and the degree of $R(+)-\alpha-\mathrm{MBA}$ is obviously larger than the case of $S(-)-\alpha-$ MBA. Obvious difference is observed on anodic characteristic peaks for $R(+)-\alpha-\mathrm{MBA}$ at $-34.8 \mathrm{mV}$ and for $S(-)-\alpha-\mathrm{MBA}$ at $6.5 \mathrm{mV}$. No obvious reduction peak appears for the amine enantiomers, showing the irreversibility of their electrochemical reactions. These suggest that chiral $\left(\mathrm{Cu}_{4} \mathrm{~L}_{4}\right)_{n}$ material has outstanding conductivity and different electrocatalytic

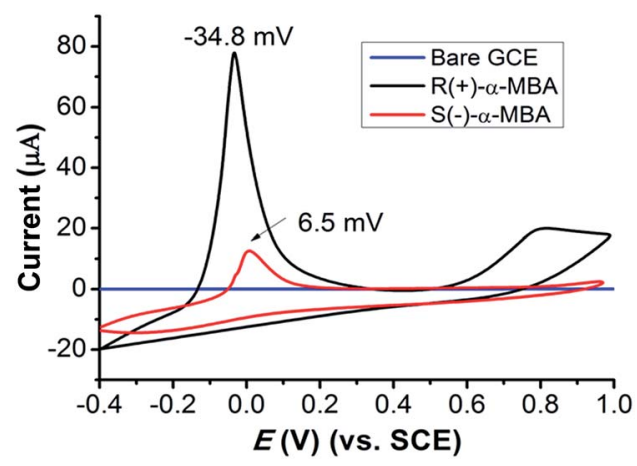

Fig. $3 \mathrm{CVs}$ of chiral $\left(\mathrm{Cu}_{4} \mathrm{~L}_{4}\right)_{n} / \mathrm{GCE}$ electrode for the detection of $0.05 \mathrm{mmol} \mathrm{L}^{-1} R(+)$ - and S(-)- $\alpha$-MBA in $0.1 \mathrm{~mol} \mathrm{~L}^{-1} \mathrm{PBS}$ (vs. SCE) at $\mathrm{pH}$ $5,50 \mathrm{mV} \mathrm{s}^{-1}$ of scan rate. 
functions on the oxidation of $R(+)$ - and $S(-)$ - $\alpha$-MBA. Based on the facts, the strategy for enantiodiscrimination of $R(+)$ - and $S(-)$ - $\alpha$-MBA enantiomers with the CMOF material can be achieved.

Differential pulse voltammetry (DPV) is a powerful method in electrochemical analysis because of its higher sensitivity and better resolution than $\mathrm{CV}^{32}$ Therefore, DPV was utilized to investigate the effect of $\mathrm{pH}$ value detected PBS solution containing the $R(+)$ - or $S(-)$ - $\alpha$-MBA.

As displayed in Fig. 4, the electrochemical behavior of $R(+)-$ or $S(-)-\alpha-\mathrm{MBA}$ is strongly dependent on the $\mathrm{pH}$ values of the aqueous solutions. $R(+)-\alpha-\mathrm{MBA}$ at examined four $\mathrm{pH}$ values overall shows a pair of well-defined oxidation peaks in the potential range of $-71 \mathrm{mV}$ to $+735 \mathrm{mV}$, and obviously higher than those of $S(-)-\alpha-$ MBA. In comparison, a characteristic peak of $S(-)-\alpha-\mathrm{MBA}$ at $\mathrm{pH} 4$ is splitting into two ones with increasing $\mathrm{pH}$ to 5,6 and 7. In both peaks, these anodic peak potentials of $R(+)$ - and $S(-)-\alpha$-MBA at $\sim 720 \mathrm{mV}$ are not suitable for assaying the enantiomers owing to their weak peak currents. Therefore, we chosen pH 5 as further chiral measurements, based on the both peak shift and difference of the peak currents from $R(+)-\alpha-$ MBA to $S(-)$ - $\alpha$-MBA, although the peak shift from $R(+)-\alpha$-MBA to $S(-)-\alpha-\mathrm{MBA}$ is significantly larger for $\mathrm{pH} 6$ than $\mathrm{pH} 5$ and $\mathrm{pH} 7$.

Under optimal pH 5, a series of $\alpha$-MBA enantiomers with different concentrations were investigated using the $\left(\mathrm{Cu}_{4} \mathrm{~L}_{4}\right)_{n}$ / GCE electrode. Fig. 5 shows the dependence of DPVs of $\alpha$-MBA enantiomers on the concentrations. The two anodic peaks for $R(+)-\alpha-\mathrm{MBA}$ at $-100.3 \mathrm{mV}$ and for $S(-)-\alpha-\mathrm{MBA}$ at $-84.2 \mathrm{mV}$ are clearly to be distinguished, and shows successive enhancement on increasing the concentration of the enantiomers. And the oxidization degree of $R(+)-\alpha$-MBA is larger than that of $S(-)-\alpha-$ MBA. The calibration curves are obtained in the range of 0.001 to $0.1 \mathrm{mmol} \mathrm{L}^{-1}$ with a detection limit of $1.3 \mu \mathrm{mol} \mathrm{L}{ }^{-1}(\mathrm{~S} / \mathrm{N}=3)$, and the linear regression equations of $R(+)$ - and $S(-)-\alpha-\mathrm{MBA}$ can be expressed as $\operatorname{Ip}^{R}(\mu \mathrm{A})=882.1 C+19.6\left(R^{2}=0.9967\right)$ and $\operatorname{Ip}^{S}$
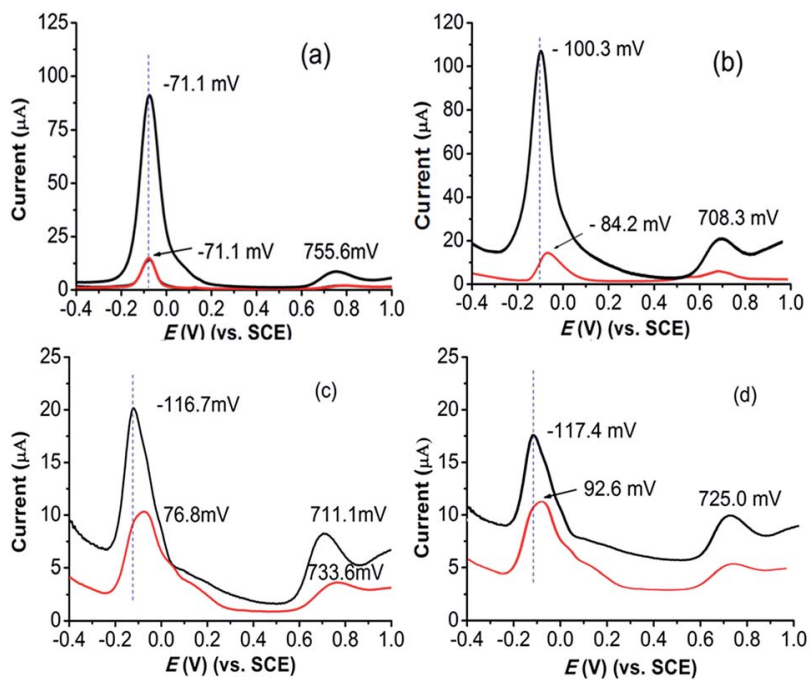

Fig. 4 DPV responses of chiral $\left(\mathrm{Cu}_{4} \mathrm{~L}_{4}\right)_{n} / \mathrm{GCE}$ electrode to different $\mathrm{pH}$ values in the presence of $0.1 \mathrm{mmol} \mathrm{L}^{-1} R(+)-\alpha-\mathrm{MBA}$ (black) and $S(-)-\alpha-$ MBA (red): (a) pH 4, (b) pH 5, (c) pH 6 and (d) pH 7. Other conditions as in Fig. 3.

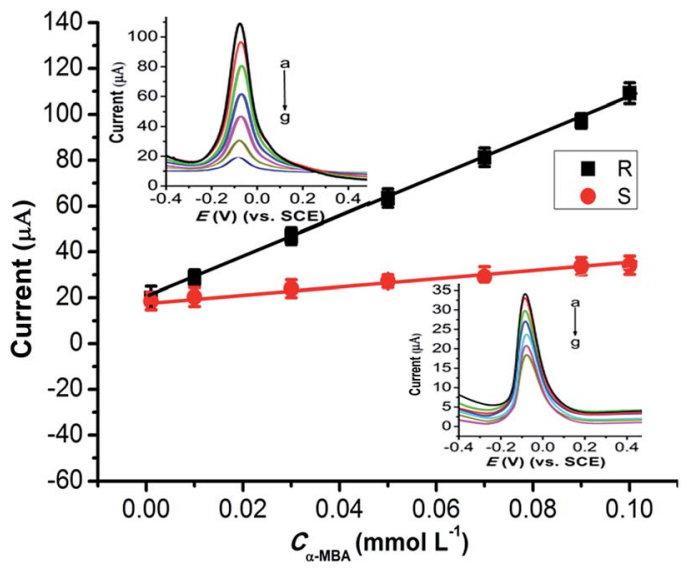

Fig. 5 DPV responses of chiral $\left(\mathrm{Cu}_{4} \mathrm{~L}_{4}\right)_{n} / \mathrm{GCE}$ electrode to different concentrations of $R(+) / S(-)-\alpha-M B A$ at $\mathrm{pH}$ 5: $0.01,0.03,0.05,0.07$, $0.09,0.10 \mathrm{mmol} \mathrm{L}^{-1}$. Inset: plot of current intensity vs. logarithmic value of $R(+) / S(-)-\alpha$-MBA concentration. Detection in $0.1 \mathrm{~mol} \mathrm{~L}^{-1} \mathrm{PBS}$ (vs. SCE) at $\mathrm{pH} 5,50 \mathrm{mV} \mathrm{s}^{-1}$ of scan rate.

$(\mu \mathrm{A})=159.5 C+19.8\left(R^{2}=0.9921\right)$, respectively. The results suggest the successful detection of $R(+)-$ and $S(-)-\alpha-\mathrm{MBA}$ enantiomers by $\left(\mathrm{Cu}_{4} \mathrm{~L}_{4}\right)_{n} / \mathrm{GCE}$ electrode in this concentration range. This attempt from only $\left(\mathrm{Cu}_{4} \mathrm{~L}_{4}\right)_{n}$ nanocrystals of inexpensive and easy synthesis is a remarkable and potentially valuable feature of this system. By contrast, the most other materials for the enantiomeric recognition require multistep syntheses of the ligand and/or the complex.

The fast and convenient determination of the enantiomeric excess in development of single enantiomer pharmaceuticals and synthesis of chiral compounds has important application because a large number of samples must be screened. ${ }^{6}$ To characterize the ability of the $\left(\mathrm{Cu}_{4} \mathrm{~L}_{4}\right)_{n} / \mathrm{GCE}$ predicting EE value of $\alpha$-MBA enantiomers in the mixture, here, the DPV analysis was performed for a series of solutions with the total concentration of $R(+)$ - and $S(-)$ - $\alpha$-MBA being kept as $0.025 \mathrm{mM}$. As shown in Fig. 6, the oxidation peaks of $R(+)-\alpha-\mathrm{MBA}$ at $\sim 100 \mathrm{mV}$ and $S(-)-\alpha-$ MBA at $\sim 84 \mathrm{mV}$ combine into a single one, which gradually shifts in positive direction as $S(-)$ - $\alpha$-MBA concentration increased. More importantly, the oxidation currents against $S(-)-\alpha-\mathrm{MBA} \%$ in the mixture of $\alpha$-MBA enantiomers exhibits a linear dependence as $S(-)-\alpha-\mathrm{MBA} \%$ increased with the correlation coefficient of 0.9903 . The results indicate that the proposed chiral sensor can rapidly and quantitatively determine enantiomeric excess in the mixture of $\alpha$-MBA enantiomers.

Enantiomers should be distinguished in the presence of chiral centers on the electrode surface. ${ }^{33}$ The fact that only chiral $\left(\mathrm{Cu}_{4} \mathrm{~L}_{4}\right)_{n}$ introduced on GCE surface recognizes $\alpha$-MBA enantiomers, suggests the formation of efficient chiral microenvironment. The oxidation of $R(+)$ - and $S(-)-\alpha$-MBA should begin their exchange electrons with electrode by passing through the CMOF layer on the electrode surface. As shown as in Fig. 5, the negative shift of oxidation potential and the significantly increasing of peak current for $R(+)-\alpha-$ MBA than that of $S(-)-\alpha$-MBA behave that $R(+)-\alpha$-MBA is easier to lose its electron on the $\left(\mathrm{Cu}_{4} \mathrm{~L}_{4}\right)_{n} / \mathrm{GCE}$ surface and faster oxidation. The 


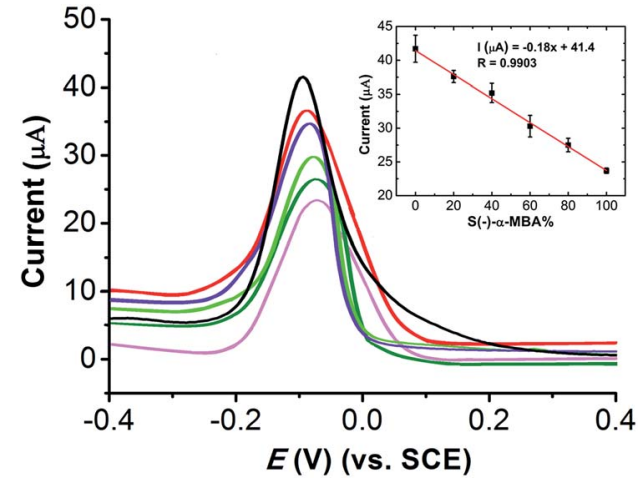

Fig. 6 The DPV for $S(-)-\alpha-M B A \%$ in the mixture of $\alpha$-MBA enantiomers. Inset: linear relationship between $S(-)-\alpha-M B A \%$ and the oxidation currents. Detection in $0.1 \mathrm{~mol} \mathrm{~L}^{-1} \mathrm{PBS}$ ( $v$ s. SCE) at $\mathrm{pH} 5,50 \mathrm{mV} \mathrm{s}^{-1}$ of scan rate. Error bars represent standard deviation for three independent measurements.

present success must result from the interaction between the chiral host, $\left(\mathrm{Cu}_{4} \mathrm{~L}_{4}\right)_{n}$ and $\alpha$-MBA enantiomers favouring enantioselectivity during the adsorption process. The interactions can be explained by three-point interaction model between the host and analytes, ${ }^{34}$ and at least one of these interactions must be stereoselective. ${ }^{1}$ As described above, the structure of $\left(\mathrm{Cu}_{4} \mathrm{~L}_{4}\right)_{n}$ crystal, possesses the guest-free chiral channels and richphenyls at wall perpendicularly with the coordination layers. A remarkable increase of $R(+)-\alpha$-MBA in the electrochemical response indicates that the more matching of the stereoscopic configuration between conformation of $R(+)-\alpha$-MBA molecule and chiral $\left(\mathrm{Cu}_{4} \mathrm{~L}_{4}\right)_{n}$ nanocrystals than case of $S(-)-\alpha$-MBA, which should be the major interaction force in the recognition. Besides this, the weak interactions like $\pi-\pi$ stacking, hydrogen bonding, hydrophobic interaction and dipole-dipole interactions may also play some role.

In summary, we have successfully synthesized a new 2D homochiral $\left(\mathrm{Cu}_{4} \mathrm{~L}_{4}\right)_{n}$ with guest-free chiral channels. The chiral electrochemical sensor assembled with $\left(\mathrm{Cu}_{4} \mathrm{~L}_{4}\right)_{n}$ nanocrystals shows excellent performance for selective oxidation recognition $R(+)$ - and $S(-)-\alpha$-MBA. This is the first attempt to directly apply a CMOF to discriminate $\alpha$-MBA enantiomers. The features of this new approach are simplicity, rapidity and sensitivity. The CMOF-based sensor provides a promising platform for studying the application of CMOFs in area of chiral electrochemistry.

\section{Acknowledgements}

This work was supported by the National Natural Science Foundation of China (Grant No. 20971080), and the Natural Science Foundation of Shandong Province (Grant No. ZR2013BM009) and the Project of Shandong Province Higher Educational Science and Technology Program (Grant No. J13LD53).

\section{References}

1 Y. W. Peng, T. F. Gong, K. Zhang, X. C. Lin, Y. Liu, J. W. Jiang and Y. Cui, Nat. Commun., 2014, 5, 4406.
2 C. Wattanakit, Y. B. Saint Côme, V. Lapeyre, P. A. Bopp, M. Heim, S. Yadnum, S. Nokbin, C. Wattanakit, J. Limtrakul and A. Kuhn, Nat. Commun., 2014, 5, 3325.

3 X. Kuang, Y. Ma, H. Su, J. Zhang, Y. B. Dong and B. Tang, Anal. Chem., 2014, 86, 1277.

4 C. Liu, B. Wang, J. Diao and Z. Zhou, RSC Adv., 2016, 6, 59842.

5 M. Lämmerhofer, J. Chromatogr. A., 2010, 1217, 814.

6 T. J. Wenzel and J. D. Wilcox, Chirality, 2003, 15, 256.

7 G. Mirri, S. D. Bull, P. N. Horton, T. D. James, L. Male and J. H. R. Tucker, J. Am. Chem. Soc., 2010, 132, 8903.

8 E. G. Shcherbakova, T. Minami, V. Brega and T. D. James, Angew. Chem., 2015, 54, 7236.

9 J. Tian and A. Rustum, RSC Adv., 2016, 6, 83020.

10 S. Sheybani, T. Hosseinifar, M. Abdouss and S. Mazinani, RSC Adv., 2015, 5, 98880.

11 S. Farzaneh, E. Asadi, M. Abdouss, A. Barghi-Lish, S. AzodiDeilami, H. A. Khonakdar and M. i. Gharghabi, RSC Adv., 2015, 5, 9154.

12 G. Vlatakis, L. I. Andersson, R. Muller and K. Mosbach, Nature, 1993, 361, 645.

13 M. O. Ramstro and R. J. Ansell, Chirality, 1998, 10, 195.

14 L. X. Chen, S. F. Xu and J. H. Li, Chem. Soc. Rev., 2011, 40, 2922.

15 T. Chang, Y. Liu, X. Yan, S. Liu and H. Zheng, RSC Adv., 2016, 6, 66297.

16 L. X. Chen, S. F. Xu and J. H. Li, J. Mater. Chem., 2012, 22, 3360 .

17 D. W. Kimmel, G. LeBlanc, M. E. Meschievitz and D. E. Cliffel, Electrochemical sensors and biosensors, Anal. Chem., 2012, 84, 685.

18 K. Tanaka, T. Muraoka, Y. Otubo, H. Takahashi and A. Ohnishi, RSC Adv., 2016, 6, 21293.

19 M. Yoon, R. Srirambalaji and K. Kim, Chem. Rev., 2012, 112, 1196.

20 X. Q. Wu, J. G. Ma, H. Li, D. M. Chen, W. Gu, G. M. Yang and P. Cheng, Chem. Commun., 2015, 51, 9161.

21 L. Yang, S. Kinoshita, T. Yamada, S. Kanda and H. Kitagawa, Angew. Chem., Int. Ed., 2010, 49, 5348.

22 H. Ji, S. Hwang, K. Kim, C. Kim and N. C. Jeong, ACS Appl. Mater. Interfaces, 2016, 8, 32414.

23 J. J. Gassensmith, J. Y. Kim, J. M. Holcroft, O. K. Farha, J. F. Stoddart, J. T. Hupp and N. C. Jeong, J. Am. Chem. Soc., 2014, 136, 8277.

24 P. H. Ling, J. P. Lei and H. X. Ju, Biosens. Bioelectron., 2015, 71, 373.

25 W. J. Ma, Q. Jiang, P. Yu, L. F. Yang and L. Q. Mao, Anal. Chem., 2013, 85, 7550.

26 Y. C. Fu, P. H. Li, L. J. Bu, T. Wang, Q. J. Xie, J. H. Chen and S. Z. Yao, Anal. Chem., 2011, 83, 6511.

27 O. K. Farha and J. T. Hupp, Acc. Chem. Res., 2010, 43, 1166. 28 J. H. Wang, M. Li and D. Li, Chemistry, 2014, 20, 12004.

29 D. Bradshaw, T. J. Prior, E. J. Cussen, J. B. Claridge and M. J. Rosseinsky, J. Am. Chem. Soc., 2004, 126, 6106.

30 M. Breuer, K. Ditrich, T. Habicher, B. Hauer, M. Keßeler, R. Sturmer and T. Zelinski, Angew. Chem., Int. Ed., 2004, 43, 788 . 
31 H. K. Kim, W. S. Yun, M.-B. Kim, J. Y. Kim, Y.-S. Bae, J. D. Lee and N. C. Jeong, J. Am. Chem. Soc., 2015, 137, 10009.

32 Y. Zhang, Y. Wang, H. Wang, J. H. Jiang, G. L. Shen, R. Q. Yu and J. Li, Anal. Chem., 2009, 81, 1982.
33 L. Chen, K. L. Li, H. Zhu, L. C. Meng, J. T. Chen, M. X. Li and Z. W. Zhu, Talanta, 2013, 105, 250.

34 Y. Liu, W. Xuan and Y. Cui, Adv. Mater., 2010, 22, 4112. 